\title{
علوم العربية ومنهجية الجمع بين القراءتين
}

\section{* عادل الثيخ عبد الله}

إن مصطلح (الجمْعُ بينْ القراءتين) هُقْتبسٌُ من العلواني 1 الذي استلهمه من فعلي الأمر في سورة العلق؛ حيث قال الله تعالى آمرا رسوله الكريم صلى الله عليه وسلم "اقْرَأ باسْم ربّك الّْذي خلق، خلق الإنْسان منْ

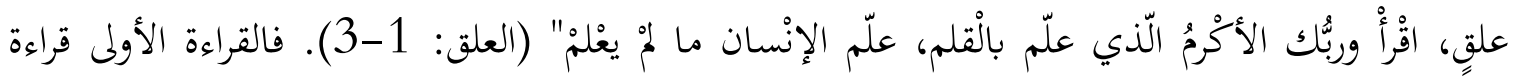
وحي باسم الله تعالى، والثانية قراءةُ الخلْق ودراسة الوجود. 2ُ وهاتان القراءتان تُمثّلان كتابين يجب قراءهما: وهما كتاب القرآن المعجز والكون الذي يمثل كتابا مفتوحا.

مقصد القراءة العقدية: هو إقامة الإنتاج العلمي للأمة الإسلامية على هدى الإسلام؛ محتوى، ومنهاجا، بينما تمدف القراءة الكونية إلى احتواء كل معطيات الفكر الإنساني -في كافة ميادين المعرفة- التي لا تتعارض مع مبادئ الدين الإسلامي. فالقراءة الكونية يقوم بها العقل الذي يُُرّكَك، ويضْبط حواس الإنسان التي من خلالما يتلقي المدد المعرفي. وهذا العقل الذي (يُعقلُ) الحواس ليس مُطْلقا يهيم أنّ وكيفما شاء، وإنما (معقول) هو الآخر بالوحي الذي "يوجهة في المجالات التي تخرج عن قدرته المحدودة في المعرفة والإحاطة والإدراك. وتتمثل تلك المجالات في كل ما يتصل بعالم الغيب الذي يعتبر هو النظام المعرين الحاكم على عوالم

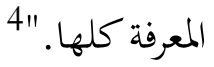

دكتوراه في علم اللغة، أستاذ مساعد في قسم اللغة العربية بالجامعة الإسلامية العالمية في ماليزيا.

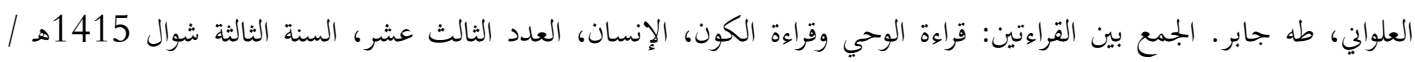

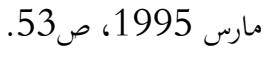

2

3

4 4 رجب، إبراهيم. ثورة التنظير في العلوم الاجتماعية، المسلم المعاصر، العدد 98، ديسمبر 2000م، ص31. 
وهاتان القراءتان لابد من التحادها في كُلِّ واحدٍ؛ يُقرآن معا وذلك "لتوحيد المعرفة الحضارية الكاملة التي تمكن الإنسان من القيام بمهام الاستخلاف."5 فالأخذ بأيهما منعزلا عن الآخر يؤدي إلى معرفة مُبتسرةٍ أي ناقصة.

وهذا الفهم هو الذي قامت عليه فكرة الأسلمة التي يتبناها المعهد العالمي للفكر الإسلامي في الولايات المتحدة الأمريكية، وتنفذ في بعضٍ من الجامعات الإسلامية، وبصورة جلية في الجامعة الإسلامية العالمية في ماليزيا، وقامت على ذات الفكرة دعوات التأصيل في جامعات السودان، والمملكة العربية السعودية، وبعض الجامعات الإسلامية الأخرى.

وفكرة الأسلمة أو التأصيل شاملة لجميع بجالات المعرفة في كافة أنواع العلوم النظرية والتطبيقية. وقد بذل المهتمون بفكر الأسلمة جهدا مقدرا في الجانب النظري والتطبيقي في كافة مجالات المعرفة. وقد حظيت العلوم الإنسانية باهتمام أكبر مقارنة بالعلوم التطبيقي؛ وما ذلك إلا لأها أكثر عرضة لغزو الأفكار غير الإسلامية، خلاف العلوم التطبيقية التي لا يؤثر فيها فكر ما؛ فهي علوم من الممكن وصفها بأها علوم محايدة، أي لا تعكس فكرا ما، فالطب مثلا هو هو سواء كان في بلاد إسلامية أو نصرانية أو يهودية، وكذلك الهندسة والصيدلة وغيرها من العلوم المشاهة.

ويبدو لمن يستعرض الإنتاج الفكري للأسلمة أن البحث في بجالات أسلمة علوم العببية قليل مقارنة بالعلوم الإنسانية الأخرى كالاقتصاد، وعلم النفس وعلم الاجتماع. ومعظم هذا القليل استأثرت الدراسات الأدبية بنصيب الأسد منه؛ وما ذلك إلا لأن حقل الأدبيات أكثر قابلية للتأثر بالفكر الآخر من اللغويات التي تُماثلُ - في معظم موضوعاها- العلوم البحتة كالكيمياء والفيزياء والرياضيات. والشاهد على ذلك أنه يوجد كم هائل من الدراسات والمؤلفات في ميدان الأدب الإسلامي. كما وأنه في معظم اللقاءات وحلقات النقاش التي عقدت في هذا الشأن كان حظ اللغويات ضئيلا، وعلى سبيل المثال ففي (ندوة الإسلامية) في اللغة العربية وآداها التي عقدت في الجامعة الإسلامية العالمية في ماليزيا، قدمت ثمانية بحوث؛ منها ستة عن 
الأدب وثنتان فقط عن اللغويات.6 وفي ميدان اللغويات لا توجد إلا اجتهادات قليلة. ففي جانب ألف الأستاذ أكرم سعد الدين وآخرون (سلسلة القلم)7 لتعليم العربية لناطقيها وغيرهم. وفي الجانب النظري قدم طه جابر العلواني آراء واجتهادات قيمة مبثوثة في سلسلة اللقاءات والمحاضرات التي يلقيها في (المعهد العالمي للفكر الإسلامي) وكتاباته في (مجلة المسلم المعاصر) و(مجلة إسلامية المعرفة). وفي هذا المجال النظري ألف أحمد شيخ عبد السلام كتابا عنوانه "مدخل إسلامي للغويات العامة". وله اجتهادات أخرى في هذا الميدان. وثمة تعليل آخر يبرر ندرة البحث في أسلمة علوم العبية ألا وهو خصوص العلاقة بين العبية والدين الإسلامي. يضاف إلى ذلك غموض فهم دلالة مصطلح الأسلمة لكثيرين. لقد فرض هذا الارتباط بين العربية والإسلام وغموض المصطلح سؤالا تقليديا يُجابه به القائمون على أمر الأسلمة بسؤال اعتراضي تقليدي ألا وهو:

\section{هل علوم العربية في حاجة إلى أسلمة؟}

وهذه الدراسة التي بين أيدينا تحاول الإجابة على هذا التساؤل وأن تصوغ تصورا لمفهوم أسلمة اللغويات، وتخُطّ أمثلة تومئ بها إلى مسارات الأسلمة؛ وما ذلك إلا لأن تحديد المسارات الكلية الشاملة للأسلمة لا يككن حصرها، واستيفاؤها في دراسة واحدة.

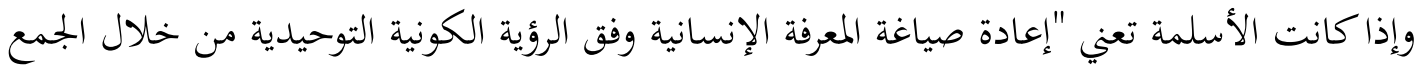
بين القراءتين: قراءة الوحي وقراءة الكون"، 8 فإن ذلك قد تم. وعليه فإنه يبدو من نافلة القول الحديث عن أسلمة العربية؛ فاللغة العربية قد قرئت قراءة وحي، عندما نزل جبريل عليه السلام بقوله تعالى "إقرأً باسْم ربّك

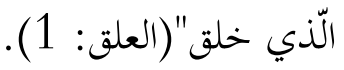

6 7

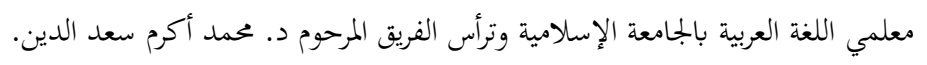
8 
كانت تلك اللحظة نقطة تحول كبيرة في تاريخ العربية؛ وكانت ميلادا لدور رسالي وحضاري كبير تقوم به العربية، بل كانت لحظة ميلاد عربية جديدة ليست كتلك العربية الجاهلية. لقد أسلمت العربية؛ فهذبت من الحوشية، ومن اللفظ الغريب، واكتسبت كثير من الألفاظ الجاهلية دلالات إسلامية.

لقد صوّر ابن فارس أثر القرآن في العرب والعربية قائلا:" لقد كانت العرب في جاهليتها على إرث من إرث آبائهم في لغاهم وآدابهم ... فلما جاء الله بالإسلام حالت أحوال، ونسخت ديانات... ونقلت من اللغة ألفاظ من مواضع إلى مواضع أخر وزيادات زيدت، وشرائع شُرّعت... كان مما جاء في الإسلام ذكر المؤمن والمسلم والكافر والمنافق، وإن العرب إنما عرفت المؤمن من الأمان والإيمان من التصديق..وكذلك الإسلام والمسلم، إنما عرفت منه إسلام الشيء ثم جاء في الشرع من أوصافه ما جاء كما جاء الإسلام بدلالات لكلمات أخر لم تكن معهودة لها كالفسوق والصلاة والزكاة والإيمان والركوع والسجود والخشية والخشنوع وغير ذلك من الألفاظ الدينية."

وتبع ذلك أن اللغة سلوك فردي، عدلت من خطاب جاهلي إلى سلوك إسلامي قويم في النثر، والشعر، وسائر الكلام اليومي. ذلك أن المسلمين كانوا يقتدون بالرسول صلى الله عليه وسلم قولا وفعلا. فالرسول صلى الله عليه وسلم هو المثال الذي انتهى إليه الكمال اللغوي. يقول الجاحظ: إن الرسول صلى

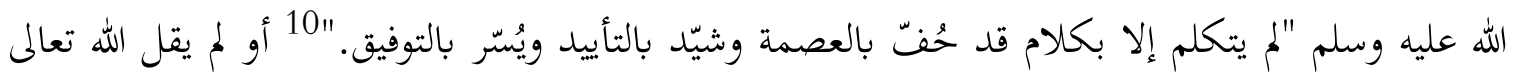

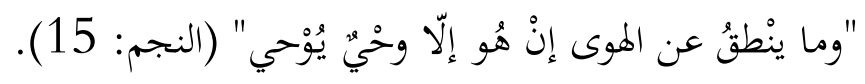

وفي القرآن الكريم والسنة النبوية الشريفة توجيهات وإشارات للكيفية التي بها يكون القول طيبا، ولما ينبغي أن يكون عليه سلوك الفرد. وعلى المستوى الاجتماعي فالإسلام قد وحّد العرب لغويا، وصاروا يتحدثون لهجة واحدة، هي لهجة قريش. ولولا الإسلام لتطورت كل لهجة إلى لغة مختلفة كما حدث للاتينية التي انقسمت إلى لغات أوربا الحميثة.

$$
9
$$

الجاحظ، أبو عثمان عمر بن بحر. البيان والتبيين، (تحقيق وشرح عبد السلام عمد هارون) القاهرة: مكتبة الخانجي، 1968م، ج2، 
أما القراءة الكونية فقد كانت عندما هبّ فطاحل الأمة لمقابلة التحديات العلمية من انحراف للقراءات وتصحيفٍ فيها، فخلقوا علوم اللغة من نحو وصرف وبلاغة ومعجمية. إذن فتلك العلوم، كما اتفق فيها، إسلامية النشأة. وفي هذا يقول شوقي ضيف: "إن العلوم الإسلامية كلها قد قامت لخدمته (أي لخدمة الإسلام)، فهو الذي هيأ بقوة لنهضة العرب العلمية."11 ويقول سزكين: "لقد بدأت الدراسات اللغوية في أبسط صورها بعد تدوين المصحف العثماني وفي إطار دراسة القرآن الكريم." "12 ولم يكن للعرب دوافع قومية عندما بدأوا يخطون علومهم كما زعم بذلك أبو سعيد محمد عبد المجيد في ذيل قوله " إن الأسس التي بنيت عليها نشأة الصرف، هي أسس إسلامية مفادها الحرص على أداء القرآن أداء صحيحا، بجانب دوافع قومية عربية واجتماعية، سياسية وغيرها."

فالإمام علي رضي الله عنه (ت 40هـ) لم يكن مدفوعا بعصبية أو قومية عندما عهد إلى أبي الأسود الدؤلي (ت 69هـ) صناعة النحو. ولم يعرف عنه ذلك إطلاقا. بل وما كان الدافع القومي ليظهر في عصر صدر الإسلام الذي نبذ القومية، وجعل المسلمين أمة واحدة.

إلا أن هذا لا يعني أن القراءتين قد اكتملتا، وأن أبواب الاجتهاد اللغوي قد غُلّقت. وإن كان هذا هو الواقع فإن فيه مناقضة مع سنن الحياة التي من لوازمها التطور والنماء اللذين لن يوجدا بدون بتديد فكري يستلهم روح العصر. وما دامت الأسلمة من أنشط آليات بتديد فكر الأمة في هذا العصر، فهي تضحى مطلبا لازما لتجديد فكرنا اللغوي الراهن الذي ران عليه الجمود في كثير من جوانبه واغترب عن ماضيه في أخص ميزاته، وعجز عن استيعاب كثير من معطيات العصر.

حقا إن علوم العربية في حاجة إلى أسلمة، بيد أها تختلف عن أسلمة ججالات المعرفة الأخرى كالاقتصاد، وعلم النفس، وعلم الاجتماع؛ وما ذلك إلا لخصوصية العلاقة بين العربية والإسلام. وهذا

$$
\text { 12 } 11
$$

سزكين، فؤاد. تاريخ التراث العربي، (ت د. محمود فهمي حجازي ود. فهمي أبو الفضل) القاهرة: الهيئة المصرية العامة للكتاب،

عبد الجيد، أبو سعيد محمد. "الأسس الإسلامية في الدراسة الصرفية "، ندوة المنهجية في اللغة والأدب. 1998م، ص1998/2/7م، الحامة 
الاختلاف وهذه الخصوصية -كما سبقت الإشارة إليهما- نتجتا من طبيعة نشأة علوم العربية والعلوم الإنسانية الأخرى؛ إذ إن معظم العلوم النظرية وفدت بمفاهيمها الحديثة إلى العالم الإسلامي من الغرب فهي غربية المولد. أما علوم العربية فهي كما أسلفنا إسلامية المنشأ، إلا أن بعضا من مجالاتا، وخاصة علم اللغة التطبيقي، وعلم اللغة الحديث قد ولدا في الغرب. وكما هو معلوم فإن العببية وعلومها التي نشأت إسلامية قد تعرضت كما تعرضت مجالات المعرفة الإسلامية والعربية الأخرى لتبديل وتحريف و تأثير في مرحلة تاريخية تالية لعصر النبوة والراشدين؛ وذلك نتيجة لظروف سياسية وفكرية.

يضاف إلى ذلك أها -أي المعرفة الإسلامية والعربية- قد أصابها الجمود فتخلفت منهجيا وهذه الحالة من التردي في العربية وعلومها لتدعو إلى الإصلاح العقدي والمنهجي بإعادة قراءها بناء على قراءتي الوحي والكون وهذا هو جوهر أسلمة المعرفة وما تحاوله هذه الدراسة أيضا. غير أن مفهوم الأسلمة الذي تتبناه هذه الدراسة يختلف عما عليه في بقية العلوم الاجتماعية الأخرى. إنه يعني: التأصيل والتجديد. فما مفهوماهما؟ تدل كلمة (التأصيل) على الرجوع إلى الأصل ونبذ التقليد والتبعية والاغتراف من المورد الرائق الذي قد هل منه رواد علوم العربية الأصلاء أمثال الخليل بن أحمد الفراهيدي، وأبي الأسود الدؤلي، ونافع بن الأزرق،

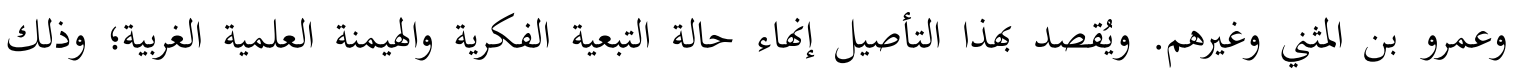
لاستقلال الأمة معرفيا.

وتفعيل التأصيل - كما يرى الباحث- ما هو إلا تنقية العربية وعلومها من كل المؤثرات، والأفكار التي تتعارض مع تعاليم الإسلام مع إحياء المنهجية العلمية الواقعية التي طرقها لغويو التراث. إذن فالتأصيل ذو محورين: محور عقديُّ وآخر منْهجيُ.

فالتأصيل العقدي هو تأصيل للمعرفة اللغوية؛ ويكون ذلك باسترجاع المعرفة اللغوية التراثية مباشرة من مظاها في كتب التراث، بغرض تمثلها واستيعاها في درسنا اللغوي المعاصر؛ لأن المعرفة اللغوية العربية قامت أصلا خادمة لعلوم الدين، ومنه استمدت حياها. إذا معرفة غير مشوبة بكدر فكري. فالأمثلة مستقاة من مكونات العقل الإسلامي العربي فقط. وهي القرآن الكريم وحديث الرسول صلى الله عليه وسلم وحكم العربي وأشعارهم وبتاربهم. وهذا الفكر قد نبت في أرض العرب ولم يتأثر بفكر آخر. 
إن كثيرا من المعارف الخاصة بعلم اللغة طرقت من قبل، ونقلت إلى الغرب ثم جاءتنا مرة أخرى عن طريق الغرب مع تبديل، ونقص، وتريف، منسوبة إلى غير أهلها. ويعني التأصيل المنهجي: تمثل المنهجية التي اتبعها اللغويون السابقون في تقنين اللغة والتأليف؛ وما ذلك إلا لأن هذه المنهجية تتناسب والفكر اللغوي العربي. وما دام إرث الأمة غنيّا في معرفته، حافلا بمنهجيّة فعلام التبعية والذيلية؟ ولم لا نستقلُّ بأنفسنا، ونستقي من بحر التراث مباشرة، وفجر ما عداه؟ كما قال المتببي في ممدوحه:

$$
\begin{aligned}
& \text { قواصدُ كافُورِ تواركُ غُيْه ومنْ قصد البحرِ استقلّ السّواقيا } \\
& \text { فأي مصدر معريف يضارع عباب الأمة الإسلامية الزخّار؟ }
\end{aligned}
$$

أما (التجديد) فهو أيضا يقوم على: محور عقدي، وآخر منهجي. ويُعنى بالأول بتحاوز دلالة التأصيل المشار إليها سابقا والمتمثلة في غربلة الفكر اللغوي من القضايا الفكرية التي تتعارض مع ديننا الحنيف، إلى توجيه اللغة وجهة رسالية مع عصرنة علم اللغة وتحديث اهتماماته ومضامينه؛ وذلك من أجل ارتقاء، ونماء الواقع العلمي المتخلف للأمة. أما التجديد المنهجي فيعنى به إقامة الدرس اللغوي على منهجية علمية حديثة.

\section{لم التجديد؟}

ثمة تبريرات عدة تسوقنا نهو تجديد الفكر اللغوي العربي، نعدد منها بإيجاز ما يلي:

أولا: لو نظرنا في هذا الفكر اللغوي العربي نجده موسوما بحالة من الجمود الفكري، وليس ثمة عطاء

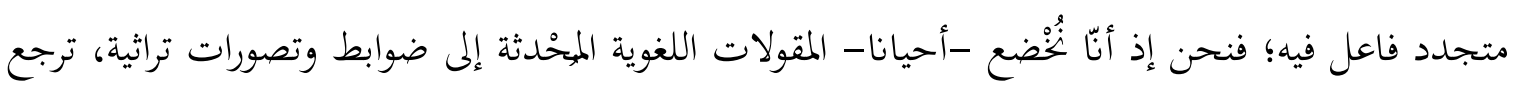
بنا إلى أوائل البعث اللغوي العربي أي عصر التدوين اللغوي ظانين أنه ليس في الإمكان أفضل مماكان. 
ثانيا: إن موروثنا اللغوي يتألف من خليط من المعلومات والنصوص والتأويلات والشروح غير مبوبة ولا مصنفة ولا مصفاة؛14 وهذا مايدعونا إلى النظر فيها مرة أخرى لقراءتا وفق مستجدات العصر الراهن ومصلحته.

ثالثا: تتضمن النصوص التراثية بعض الملابسات التي تُنقص من كمالها، وتُشكك في صحتها. ومن ذلك قضية الانتحال التي اعتادها كثير من الرواة وبعض الأعراب الذين امتهنوا قضية بيع اللغة؛ أي إخراج ما عندهم من المفردات اللغوية مقابل أجر يدفعه لهم جامعو اللغة. وصارت الرواية مصدر رزق لكثير من الاعراب الذين ينتجع إليهم الرواة أو يرتحلون هم إلى الحضر لسوم ما عندهم من اللغة.

رابعا: لم يدون كثير من أدبيات الحركة العلمية يومذاك. ويطلق على ما لم يدون مصطلح "المسكوت عنه". ويشمل الجوانب العلمية التي لم يشملها اهتمام الذين دونوا المعارف العلمية. وليس ذلك لأنما لم تدخل في دائرة العلم، وإنما أهملت بدوافع فكرية ومن ذلك تعريب لغة الدواوين من اللغات الفارسية والرومية، وذلك لأن الإدارة في أول عهود الدولة الإسلامية كانت بيد خبراء أجانب يتحدثون تلك اللغات.

قد تبدو في ذلك مناقضة، لمنْ لمُ يُتأن فيستفهم: كيف يُجمع بين تأصيل المعرفة وبحديدها؟.. وكيف يجمع بين المنهجية القديمة والحديثة؟

ويقيني أنه ليس ثمة تناقض وتضاد في ذلك؛ فالتجديد والتأصيل لازمتان من لوازم سنن التطور السليم. فالتأصيل هو بمثابة الأس الذي يُبنن عليه أي جديد، وعدم التجديد سكون؛ فلا يجتمع تطور مع سكون. هذا من ناحية. ومن ناحية أخرى فإن كل القديم ليس لازما تأصيله؛ إذ منه ما يُبلى ومنه ما يتجاوزه الزمان؛ فما كان صالحا بالأمس ليس من الضروري أن يكون ملائما لليوم ولغدٍ؛ فمن القديم كله ما يؤخذ، ومنه ما يُرد، ومنه ما يجب استحياؤه إن كان ميتنا.

إن التجديد المبتغى ليس كذلك الذي دعا إليه في زمن مضى من تاريخ الأمة مغرضون أمثال سلامة موسى وجورجي زيدان وقاسم أمين ولويس عوض ويعقوب صنوع ولطفي السيد وغيرهم من دعاة التجديد

$$
14
$$


المغرض الذين رأوا أن التجديد يكون باستعمال الحرف اللاتيني، واستعمال العامية، واستبدال علامات الإعراب بحروف تكتب. 15 إن التجديد المرسوم هنا تجديد مقيد بالوحي ومصلحة الأمة التي يجب أن تكون

$$
\text { وفق هدى الوحي. فالوحي من قبلُ ومن بعدُ. }
$$

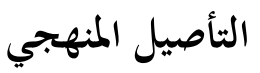

والذي يجب ذكره هنا هو: أن علماء الغرب قد استفادوا من الدراسات اللغوية العربية. وألفوا على هج ما صنع العرب. ولئن كان للعرب فضل الريادة فللغرب فضل التطوير في حقل علم اللغة، ذلك أفم ارتقوا بمناهج البحث، وطرقوا مواضع جديدة لم ينتبه لها اللغويون العرب مثل: علم اللغة التاريخي، وعلم اللغة الجغرافي، وعلم اللغة المقارن. كما أغم مزجوا الدراسات اللغوية مع دراسة العلوم الإنسانية، فاستولدوا علم اللغة التطبيقي applied linguistics. و"يعتبر القدامى من علمائنا -بحق - أساتذة لعلماء الغرب- إبان هضتهم في هذا الجانب اللغوي،

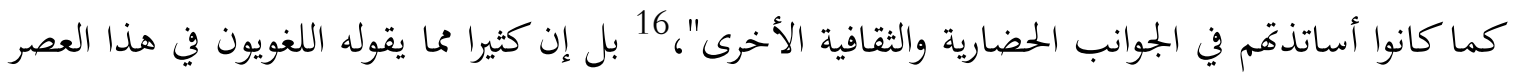
نقلوه من علماء اللغة العرب. يقول حمّاد "والحقيقة التي لا تقبل جدلا هي أن علوم اللغة المتعددة قد درست من قبل العلماء العرب مع بداية النهضة العلمية. ومنذ ظهور مدرسة البصرة والكوفة في بغداد، ولا يوجد مجال للشك في أن معظم علوم اللغة النحوية، والصرفية، والمعجمية، والاشتقاقية، والدلالية، قد زرعت بذورها عند العرب القدماء، وأن الدارس يستطيع أن يجد ذلك لدى الأصمعي، والخليل بن أحمد، وأبي زيد الأنصاري، وأبي عبيدة، والفراء، والكسائي، وغيرهم من علماء ذلك العصر، وتزامن مع هذه الطبقة من العلماء طبقة أخرى كان لها دور كبير في دراسة هذه العلوم نذكر منهم الجاحظ وابن جني وابن فارس، وعبد القاهر، والسيوطي وغيرهم."17

15 15زيد من الثفصيل ونغنيد دعاويهم في اللسان العربي والإسلام أنظر: معاً في موكة المواجهة. تأليف السيد رزق الطويل، مكة المكرمة:

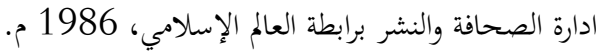

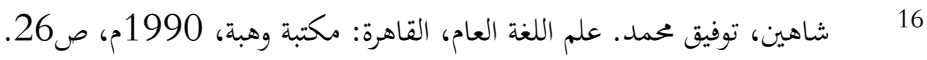

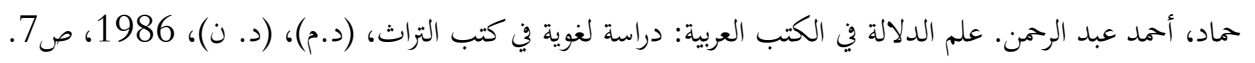


ورغم أن اللغويين القدماء ما تركوا شاردة ولا واردة في بجال اللغويات العربية، إلا أن كثيرا من اللغويين العرب المحدثين يستقون من لغويي الغرب في بعض مجالات علم اللغة بكل ضروبه. ومثالا لا حصرا، فهم يرجعون إلى بلومفيلد في مؤلفه (اللغة)، 18 وإلى نيدا في كتابه (المورفولوجيا)، 19 ودي سيسور في كتابه الذي لا يكاد يخلو منه مؤلف لغوي عربي (محاضرات في علم اللغة العام)، 20 وباي ماريو في (أسس علم اللغة)، 21 ويوهان فلك في (العربية: دراسات في اللغة واللهجات والأساليب)،22 وفندريس في (اللغة)23 وغيرهم من لغويي الغرب الذين طبعوا عقل اللغويين العرب بخصائص التفكير اللغوي الغربي، وجعلوه أسير فكرهم. 24 لا شك أن المعرفة تراث بشري مشترك، وملك مشاع بين البشر، غير أن معرفة كل أمة وليدة بيئتها، وما فصل لقوم قد لا يناسب أمة ما. ولذا فإن كان النبع تحت الأرجل فلم النجع؟ لقد اهتدى اللغويون القدماء إلى مناهج علمية تخدم القضايا العلمية التي أثاروها يومئذ. ولم يثبت دليل على كون هذه المناهج مقتبسة من أمة ما، فهي مناهج عربية النشأة. ف"إذا كانت الفلسفة هي معجزة اليونان فإن علوم العربية هي (معجزة) العرب. والحق أن ذلك العمل العظيم الذي تم في عصر التدوين على مستوى جمع اللغة وتقعيدها كان بالفعل أشبه شيء بالمعجزة."25 حقا، لقد كان ذلك العمل الجبار خرقا للعادة؛ ذلك أن العرب كانت أمة أمية لا هتم بالقراءة والكتابة؛ وليس لها من الإرث العلمي إلا ما تلوكه الألسن؛ ويتداوله الرواة. فالعلم العربي كان شفاهيا. وبتدوين اللغة وتقييدها دخلت العبية طور الدرس العلمي المنهجي.

18 Blomfield, Leonard. Langugage. Chicago. University of Chicago Press.

19 Nida, E.A. Morphology, Ann Arbor: University of Michigan Press. 1949.

20 Desaussure, Ferdinand. Course in General Linguistics, Mc Graw-Hill, 1965.

$$
\begin{aligned}
& 21
\end{aligned}
$$

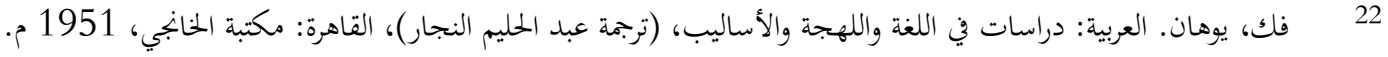

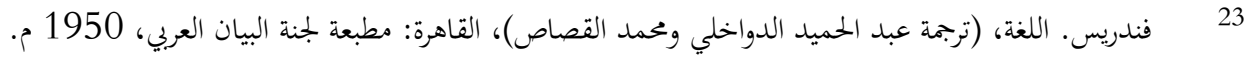

$$
\begin{aligned}
& 24 \\
& 25
\end{aligned}
$$


لقد اهتدى اللغويون العرب إلى منهجية دقيقة وصارمة في مسح اللغة وتدوينها. وتم ذلك في مراحل ثلاث متداخلة. ففي الأولى تم جمع مفردات اللغة وتفسيرها دون ترتيب. ولقد اعتمد جامعو اللغة على مصادر أساسية وهي: القرآن الكريم، والحديث النبوي والأدب القديم بشعره وأخباره وأمثاله بالإضافة إلى السماع من الأعراب في باديتهم أو حين قدومهم إلى الحضر. ومن أشهر الكتب التي تمثل هذه المرحلة كتاب " النوادر في اللغة لأبي زيد الأنصاري" (ت 215 هـ).

وفي المرحلة الثانية صنفت المفردات إلى رسائل صغيرة؛ تختص كل رسالة بسرد مفردات موضوع واحد مبنية على معنى من المعاني أو على حرف من الحروف. ويمثل هذه المرحلة كتب "الإبل" و "الشاء" و"أسماء الوحوش وصفاتا"، و"الخيل"، و"خلق الإنسان"، و"النخل والكرم"، و "النبات والشجر" للأصمعي (ت 216

أما الثالثة التي جُمعتْ فيها كل مفردات اللغة في كتاب واحد، فيمثلها الخليل ابن أحمد الفراهيدي (ت 175 هـ) الذي تفتقت عبقريته عن منهجية فذة -غير مسبوقة بل وغير (ملحوقة) حتى الآن- في كتاب

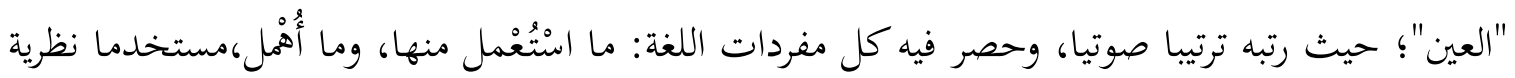
التباديل والتوافيق الرياضية. ولقد كان عمل الخليل فتحا في المعجمية العربية؛ ولا يزال الناس عيالا على منهجيته، وإن خولف أحيانا.

إن هذا التطور في المراحل الثلاثة يرتبط عضويا بخيط فكري متين. وإذا قُيّم بناء على معايير المنهجية

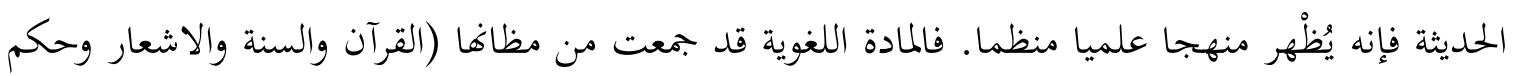
العرب والأعراب ومقولاقم) وهذه المصادر تمثل العقل الجمعي خير تمثيل. ويدل الترتيب (أي جمع ثم تدوين موضوعي فتدوين معجمي) على مدى وعي اللغويين العرب خاصة بفكرة الحقل الدلالي semantic التي قال بها اللغويون المعاصرون وسبق بها لغويو الأمة في الترتيب الموضوعي. ويكفي برهانا على field عظمة العبقرية العربية منهجيا أن الحنليل بن أحمد فعل ما يعجز عنه المحدثون في إحصاء واستقصاء اللغة.

$$
26 \text { 2 }
$$


وبالإضافة إلى المنهجية الخاصة التي ابتدعها اللغويون في جمع اللغة وكتابة المعاجم، فإغم تأثروا في المراحل التالية من مراحل التأليف في علوم اللغة بفروعها المختلفة في مناهجهم بمنهجية علوم الحديث. يقول السيوطي في مقدمة المزهر: " هذا علم شريف، ابتكرت ترتيبه، واخترعت تنويعه وتبويبه، وذلك في علوم اللغة

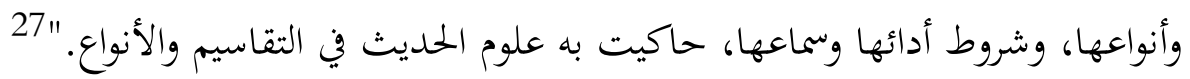

ومن المناهج التي استخدمها اللغويون العرب يومئذٍ: المنهج النقلي، والمنهج العقلي، والمنهج المعياري،

والمنهج المقارن، والمنهج التكاملي.

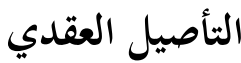

إن بعضا من مفاهيم علم اللغة التي قال بها بعض قدماء اللغويين العرب والتي وجدت طريقا إلى الفكر اللغوي القديم ما هي إلا نتاج للتأثر بالتيارات الفكرية الوثنية التي انتقلت إلى العربية عن طريق الترجمة أو روّج لها علماء عرب أُعْجبوا بالفكر اليوناني القديم.

وقد وفدت في عصرنا الحاضر -نتيجة للاحتكاك بالغرب- بعض من المفاهيم والمقولات الحديثة التي

تتعارض مع مبادئ الدين والفهم الإسلامي. ومن المؤسف أن كبار اللغويين العرب ظلوا يرددون ذات المقولات الغربية العلمانية بوعي، أو بدون وعي. ومثال ذلك نشأة الكلام عند الإنسان وبدايته.

إن هذه القضية -أي قضية نشأة اللغة- تعدّ من القضايا التي ذهب فيها علماء اللغة العرب -قديما

وحديثا- مذاهب شتى. ولمم فيها تأويلات متباينة. لقد انقسم اللغويون الرواد أنفسهم، في هذه القضية، إلى فريقين: فريق يرى أغاا توقيفية، ويتزعمه ابن فارس (ت 395هـ). ويستدل بقوله تعالى "وعلّم آدم الأسماء

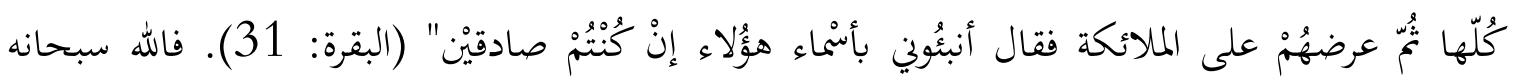

$$
27
$$

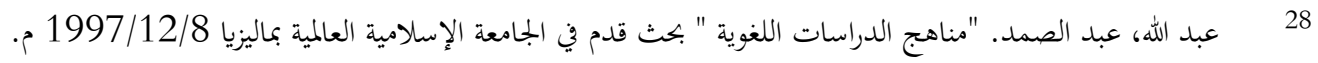


وتعالى ألم آدم عليه السلام أسماء المسميات كلها. قال ابن عباس: علمه اسم كل شيء حتى القصعة والمغرفة.

أما الفريق الآخر الذي يتزعمه ابن جني (ت 392هـ) فيرى أها من صنع الإنسان، وأها تطورت من محاكاة لأصوات الطبيعة إلى أن وصلت إلى مرحلة النضج. إن هذا المنحى من التفكير الذي قال به ابن جني ربما كان نتيجة لإطلاعه على الفكر اللاتيني؛ إذ أنه رومي الأصل.

والذي ذهب إليه ابن جني نفسه يقول به علماء اللغة المحدثون؛ إذ ادعى بعضهم أن اللغة "نشأت من تقليد أصوات الحيوان والجماد وارتكاس للرسوم والحركات، إفا بحسب زعمهم بدأت بالرسم الدال على بكلى العمل، إما بالحركة، أو بالآلة المستعملة، أو بصورة الهدف الذي يُسعى إليه، ثم انتقل هذا الرسم التعبيري إلى تلى تركي

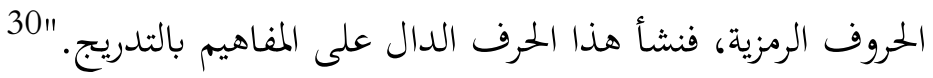

ويردد لغويون عرب محدثون مقولة فندريس الذي يرى: أن اللغة لم تولد "كحدث اجتماعي إلا يوم أن وصل العقل الإنساني إلى درجة من النمو تسمح له باستعماها."31 وملا عجزت معايير العقل الغربي في الوصول إلى نتيجة في هذا الموضوع، طالب بعضهم بعدم البحث في هذه القضية وأوصت بذلك الجمعية اللغوية الفرنسية في عام 1878م، معللين لذلك بأن العلم لا يبحث إلا فيما تؤكده المادة المحسوسة، إذ ليس لإنسان أن يصل في هذا الموضوع إلى نتيجة يطمئن إليها المنهج العلمي. وجلي أن هذا يتعارض مع الفهم الإسلامي الذي يجعل الوحي المصدر الأول للمعرفة.

إن مقولة ابن جني ومن حذا حذوه من المحدثين تتعارض مع الفهم الإسلامي الذي يمثله ابن فارس. فإنا كمسلمين، غتدي بالوحي، نسلم: أن آدم أبا البشر، وبه بدأ الخلق. وأنه رسول من الله، أوحي إليه ليبلغ رسالة الله. ويستلزم الرسالة الوسيلة اللغوية وإلا فكيف يخاطب من أرسل إليهم؟ ويستحيل أن يكون آدم وذريته قد بدأوا محاكاة أصوات الطبيعة إلى أن نمت ملكة اللغة عندهم.

$$
\begin{aligned}
& 29 \text { 2 } 30 \\
& 30 \text { 31 } 30 \\
& 31
\end{aligned}
$$




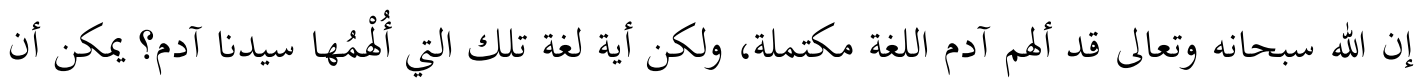
يكون الجواب محور خلاف؛ إذ ليس مهما أن تكون العربية أو السريانية أو أية لغة أخرى. فآدم عليه السلام قد ألم لغة يشر ويدعو بها ويتلو بما كتاب الله. ونتيجة لتفرق بني آدم في المعمورة، واختلاف الأقاليم التي قطنوها، نشأت عن اللغة الأولى لهجات ثم تطورت اللهجات إلى لغات. وصدق الحق حين قال "ومنْ آياته

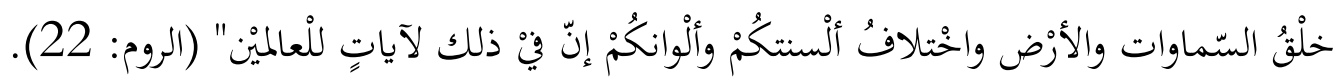

إن القول بأن اللغة قد نشأت لاحقا، وأن أعضاء الإنسان قد تطورت لتلائم وظيفته الجديدة ما هي إلا دارونية تتعارض مع ما ذهب إليه القرآن. فالله جل وعلا يؤكد في كتابه العزيز أنه قد خلق الإنسان في أحسن تقويم. وعبارة أحسن تقويم لا تعني تقويم البدن فقط، وانما تشمل تقويم كل ما يميز الإنسان عما عداه من الخلائق، ومن ذلك اللغة. يقول الله تعالى في محكم تنزيله:

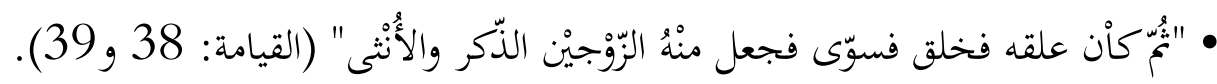
• • لسبّحْ اسْم ربّك الأعْلى الَّني خلق فسوّى" (الأعلى: 1).

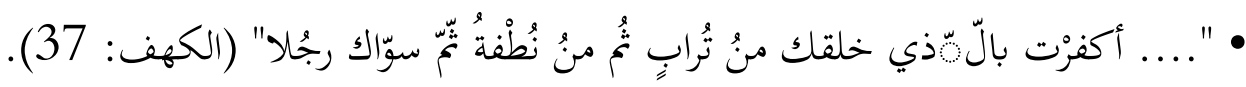
• • "ونْسِ وما سوّاها فأَلْمها فُجُورْها وتْقواها" (الشمس: 7 و 8). • • (الذّي خلقك فسوَآك فعدلك" (الإنفطار: 7).

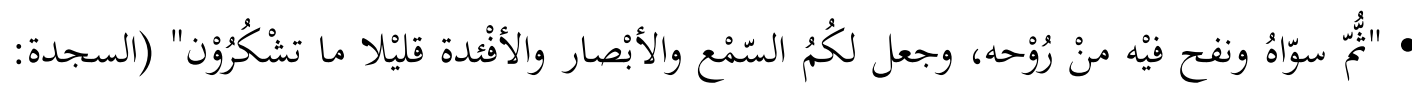

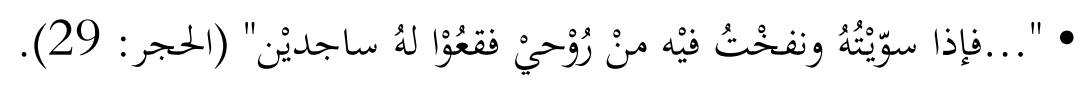

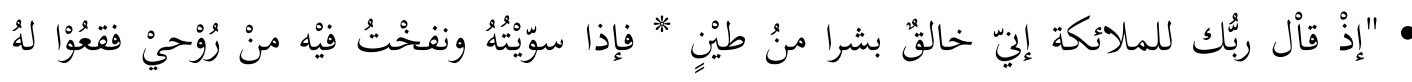

$$
\text { ساجديْن" (ص: } 71 \text { و } 72 \text { (72). }
$$


جاء في اللسان تحت كلمة (سوّى): وسوّيْتُ الشيء فاستوى أي اعتدل. 32 والاعتدال هو الاكتمال.

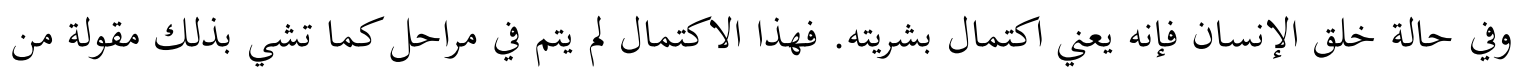
يعتقد أن النظام اللغوي للإنسان قد تكوّن لاحقا. كلا إن النظام اللغوي كما تؤكد تلك الآيات قد تم في

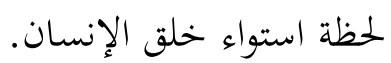

ويقول الصابوني في تفسر الآيتين 7 و9 من سورة الانفطار : "أي الذي أوجدك من العدم، فجعلك

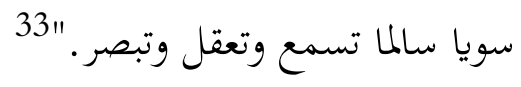

إن هذا كله ليؤكد أن الإنسان قد خلق سوي الخلق وفي أحسن تقويم. وما كان ينبغي لعلماء اللغة من

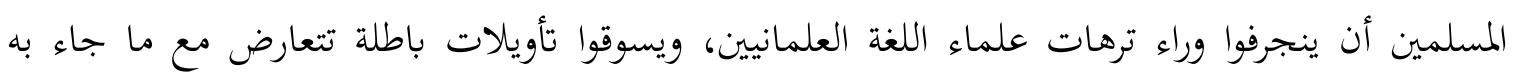
الوحي الذي يعتبر مصدر المعرفة الأول في الإسلام.

يشكل هذا النموذج الذي سقناه مثالا لقراءة تأصيلية من هدى الوحي. وهذه القراءة النموذجية

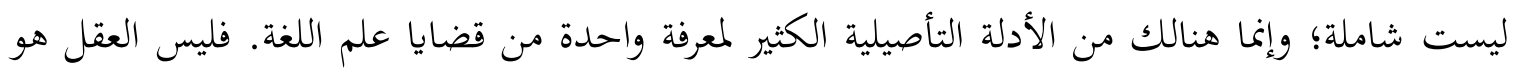

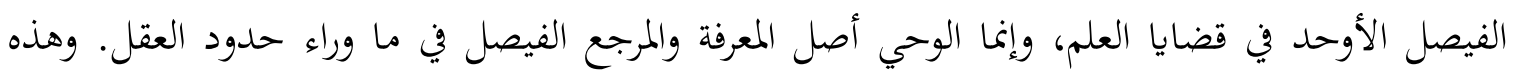

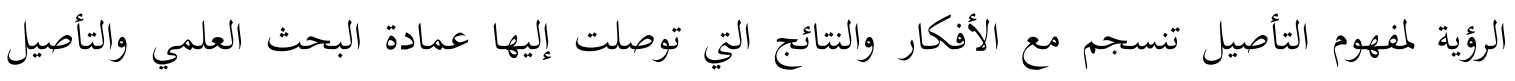
الإسلامي بجامعة الإمام عممد بن سعود عندما قامت بمراجعة بتحارب كليات العلوم الاجتماعية في بحال التأصيل. واقترحت العمادة عدة خطوات إجرائية عملية وذلك لتغعيل التأصيل منها: • تشجيع المتخصصين على دراسة أفكار العلماء الأوائل من المسلمين ونظرياقم للوقوف على الجذور الأولى للعديد من فروع العلوم الاجتماعية. • وضع منهج عام لكتابة مدخل إسلامي للعلوم الاجتماعية. • تحديد بجالات البحث في التأصيل الإسلامي للعلوم الاجتماعية.

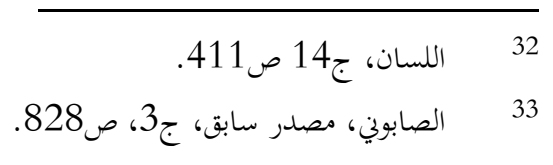


• صياغة مفاهيم التأصيل في التراث الإسلامي ومناهجه.

• (القيام بتنقية مناهج التدريس مما يخالف التوجه الإسلامي.34

\section{التجديد المنهجي}

إن التجديد المنهجي الذي يعتبر جوهر القضية الفكرية المعاصرة، يرمي إلى ممارسة الاعتقاد السليم ويسعى إلى إصلاح حال المسلمين بغية أن تستعيد الأمة دورها الريادي. 35 كما يعني تعديل المنهج وتقويمه.

وبتحيد منهج العربية يعنى إقامته على أسس علمية. ولئن كان العرب قد أسسوا منهجية علمية في البحث اللغوي، إلا أن هذه المنهجية قد ضوت في فترات ضعف الحضارة العربية. وفي هذا العصر فإن منهجية العربية وعلومها في حاجة إلى تلقيح من المنهجية العلمية الغربية المتقدمة في بحث وتعليم اللغات. والإصلاح المنهجي لا يكون بالأخذ من الغرب فقط؛ وإنما يعني أيضا إحياء المناهج القديمة التي استخدمها اللغويون العرب. فالإصلاح المنهجي هو (تأصيل وتحديث في المنهجية).

إن الذي يقارن بين منهج اللغويين الغربيين والعرب، في الدرس والبحث اللغوي، ليدرك أن البون شاسعٌ بينهما في المختوى والطريقة؛ فبينما نجد أن جامعات الغرب تواكب متطلبات العصر، بل تتقدمه، نجد أن درسنا اللغوي ما هو إلا اجترار لما قال وعمل به الأولون، ناسين أن العصر اختلف، وأن ما صلح للأمس قد لايكون صالحا لليوم. بل وإن منْ العاملين في مجال اللغويات العربية منْ يشكك في فائدة تطبيق مناهج وأفكار الدراسات اللغوية الحديثة على دراسة اللغة الفصحى؛ إذ يرون أن الأول ما ترك للآخر شيئا وكم ترك الأول للآخر

وهذا التقديس للقديم فرض قيودا على الدرس اللغوي الحديث لا ينفك منها. ومن تلك القيود قضية ترتيب أبواب النحو العربي التي ما تزال كما قال بها الخليل. ولأن أبواب النحو لا تزال كما قال بها الخليل فما تزال توجد بعض أبوابٍ في النحو والصرف مهملةٌ في الاستعمال اليومي، تشغل حيزا كبيرا في الدرس اللغوي 34

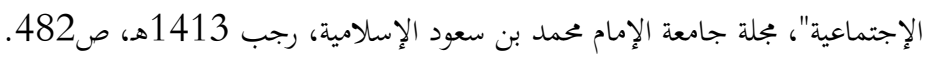
أبو سليمان، عبد الحميد. معارف الوحي: المنهجية والأداء، مؤتمر علوم الشريعة في الجامعات، عُمَّان، 1994. 
كالتصغير الذي ما ورد في القرآن إلا لكلمة واحدة، تكررت في ثلاث آيات. 36 بل وبعض الكلمات التي هجرت في الاستعمال اللغوي ما زال مدرسو الصرف يتمسكون بها. وتمتلئ كتب الدرس النحوي بكثرة الشواذ المخالف للقاعدة، والإسراف في العوامل النحوية والتعليلات. ويبدو التمسك بالقديم جليا حتى في الشواهد النحوية؛ فمعلمو النحو لايزالون يكررون قول صاحب الألفية:

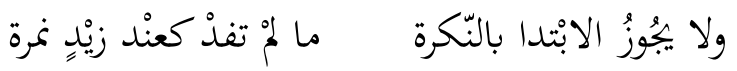
حقا لقد صدق فيهم قول من قال: ما نرانا نقول إلا معارا معادا من قولنا مكرورا وبعض الموضوعات اللغوية ذات الأهمية العملية القصوى لا تجد عناية مثل التعريب، واستيعاب كلمات جديدة من اللغات الأخرى وكيفية كتابتها. لذا ننادي بفتح باب الاجتهاد اللغوي؛ ولا نعض بالنواجز على قيود الأوائل. بل يجب أن نلقح موروثنا اللغوي بالمفيد من المنهجية الحديثة أنى وجدناها

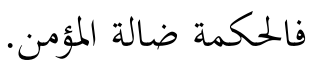

إن الذي ينظر اليوم في واقع منهجية الدرس والبحث اللغويين، ليخلص إلى: أن اللغة اليوم تدرس دراسة علمية. ويُقْصد بالدراسة العلمية: دراسة اللغة باتباع المنهج العلمي الذي يستعمل في دراسة العلوم الأخرى مثل: الكيمياء، والفيزياء، والحساب. وهذه الطريقة لا تقوم على العواطف ولا الأحكام المسبقة أو الإجحاف. فإذا قال شخص: بأن لغة ما لغة متخلفة، وأن لغته لغة متحضرة أو أن تلك اللغة لغة سهلة، وهذه لغة صعبة، فهذا الحمكم غير علمي؛ لأنه قد بُني على عاطفة، ولم يُبن على أسس علمية سليمة.

قال تعالى على لسان سيدنا يعقوب عليه السلام يخاطب ابنه يوسف عليه السلام " قال يابَّي لا تقصص رؤياك على إخوتك فيكيدوا

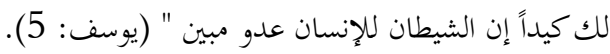

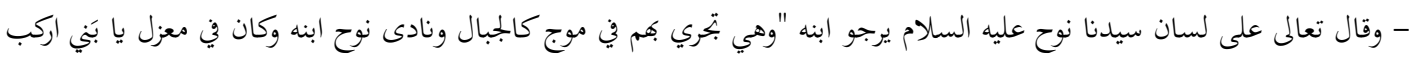
معنا ولا تكن مع الكافرين" (هود: 42). - وقال تعالى على لسان سيدنا لقمان واعظاً ابنه "يا بني إنها إن تك مثقال حبة حبة من خردل فتكن في صخرة أو في السماوات أو في الأرض يأت بها الله إن الله لطيف خبير" (لقمان: 16). 
يقوم المنهج العلمي الحديث على أسس علمية منها: الملاحظة، والتجريب، والتحليل وبناء الفرضيات، واختبار تلك الفرضيات فهذه الوسائل هي التي تقود إلى فهم سليم وصادق، عكس العواطف التي تؤدي إلى حكم جائر وغير علمي. فالإنسان إذا كره شيئا -وهذه عاطفة- فإن رأيه يكون سلبيا تجاه ذلك الشئ. وكذلك إذا أحب شيئا فإنه يصدر حكما إيجابيا نهوه.

فالمناهج العلمية الحديثة المستخدمة الآن في دراسة اللغة التي لا تنال حظها الكافي من الاهتمام والتطبيق عديدها منها: المنهج التاريخي المقارن، والمنهج الاستنباطي، والمنهج السلوكي، والمنهج البنيوي، والمنهج التجريبي.

يؤرخ لنشأة هذه المناهج الحديثة بالقرن الثامن عشر الميلادي. وهي مناهج تفسر اللغة من زوايا مختلفة ورغم تعددها، واختلاف مسمياها قد تلتقي مع بعض أحيانا. وقد نشأ اللاحق منها نتيجة لنقص رآه اللاحق في السابق أو نتيجة لاختلاف الرؤية للغة. ولذا فهي تلتقي مع بعضها أحيانا.

إن الذي يطلع على مقررات أقسام اللغة العربية بالجامعات العربية والإسلامية، ليدرك أها لا تزال تعول على المناهج القديمة فقط. ولا يزال المنهج التجريبي شيئا غريبا يطبق في حدود ضيقة. ومثال ذلك علم الأصوات التجريبي الذي يدرس نظريا وما ذلك إلا لافتقار معاهد التعليم للأجهزة والمختبرات اللغوية، أو لعدم إدراك الذين يقومون بتعليم هذه المادة لأهمية هذا الفرع من اللغويات. أما مادة الإحصاء التي تستخدم في تحليل البيانات واختبار الفرضيات فإها لا تدرس في أي قسم من أقسام اللغة العربية، وكان يجب أن توضع ضمن مفردات مادة طرق التدريس التي تدرس بطريقة نقلية ليس فيها بتحيد أو إبداع.

ومن يطلع على رسائل الدراسات العليا يجد أغها تتسم بالتكرار، وضعف المنهجية عموما وانعدام المنهجية الحديثة. ورسائل تحليل الأخطاء خير شاهد على ذلك. إذ تتبع المنهج الكمي الذي ترصد فيه أعداد الأخطاء تنازليا، ولا تعطي تفسيرا ذا قيمة لمدلول هذه الأرقام. وهذا عكس المنهج الكيفي، الذي يندر في الدراسات العليا. فالمنهج الإحصائي الكيفي يحلل، ويعلل تواتر الأرقام في أية حالة مدروسة ثم يعطي نتائج صادقة لقراءة المتغيرات. وهذا ما لا يقوم به المنهج الأول. 


\section{التجديد المعرفي}

ثمة سؤال يُطرح هنا وهو هل قدمت المعرفة اللغوية عند العرب شيئ؟

وقبل الإجابة على هذا السؤال نمهد له بقولنا: إن مصطلح علم اللغة مصطلح حديث؛ دخل اللغة العربية عن طريق الترجمة من الغرب، فالأقدمون منهم لم يعرفوا هذا المصطلح. وكان علم اللغة يعرف عندهم بفقه اللغة. وهو الفرع الذي يهتم باللغة العربية ما عدا الجانب الأدبي الذي ترك للأدباء والنقاد.

وتتشعب الدراسات اللغوية الحديثة إلى فرعين رئيسيين وهما: علم اللغة العام general linguistics بمجالات أخص من مجالات اللغة.

يتشعب علم اللغة العام إلى فروع عدة منها: علم النحو، وعلم الأصوات، وعلم المعاني وغيرها. فعلم النحو يبحث في تركيب الجملة وأنواعها. ويعرف بين اللغويين المحدثين، أحيانا، بالتراكيب structure) وهyntax) (السنتاكس). ورغم أن اللغويين العرب قد استوفوا بناء النحو العربي، إلا أن هنالك كثيرا من المحثين الذين حاولوا إقحام قضايا لغوية حديثة ظانين أفم بذلك يحسنون صنعا؛ ويكملون ما توهموه نقصا في نحونا العربي. إلا أغم جاءوا بقضايا لا تمت إلى المنطق اللغوي العربي بصلة. ومن ذلك قضية النحو التوليدي generative grammar

إن علم المعاني semantics هو الحقل الذي تدرس فيه العلاقة بين الكلمة المكتوبة أو المنطوقة وما تدل عليه الكلمة أي معنى الكلمة Word meaning. وتدرس كذلك التطور التاريخي للكلمة، أي ماذا كان معناها قديما؟ وماذا صار معناها الآن؟ والأسباب التي أدت إلى تغيير الدلالة. وهذا المجال قد عرفه العرب قبل غيرهم. وتحفل المكتبة العربية بالكثير من مؤلفات علم المعاني والبلاغة، ورغم ذلك فإن بعضا من اللغويين العرب يلجأون إلى المؤلفات الغربية في هذا الشأن. 
أما بجال علم اللغة التاريخي historical linguistics فهو البحث في تطور اللغات وتكون اللهجات والأسر اللغوية والعلاقة بين اللغات. وهذا الجلال قد سبق إليه العرب حيث تحدثوا عن التطور

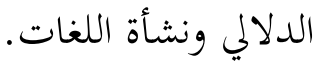

قصارى القول: إن العربية غنية في ميدان علم اللغة العام (الأصوات والصرف والمعاني). وهذه الأفرع

من المعرفة اللغوية هي التي بدأ جما العرب علومهم. غير أن منْ ينظر تارة أخرى في المعرفتين: العربية والغربية في

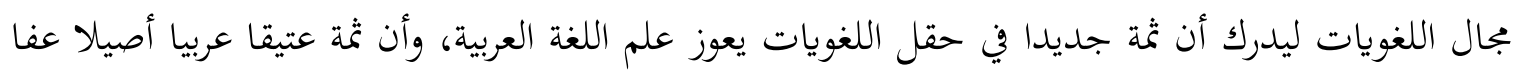

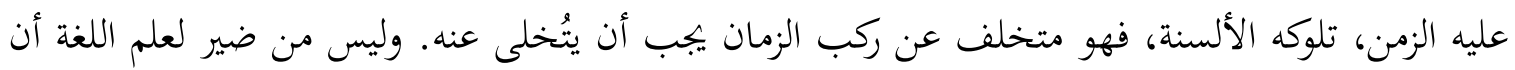

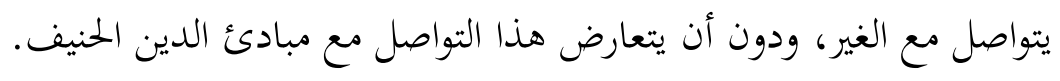

ويعتبر علم اللغة التطبيقي من أكثر المجلات اللغوية التي يحتاج العرب إلى تطويرها ومن ثم الارتقاء

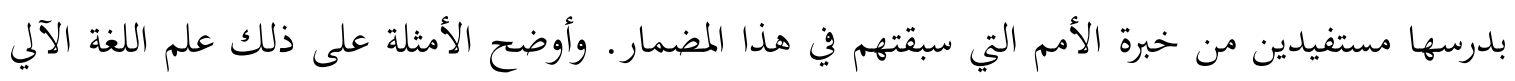
Computational Linguistics تاون. 37 وييمع هذا العلم بين الدراسات اللغوية النظرية (كعلم الأصوات والتراكيب وعلم المعاني) وعلوم الحاسوب مثل (الذكاء الاصطناعي، وتصميم النظم). وقد أنشئ هذا التخصص نتيجة لبحوث رائدة في التزبمة الآلية من اللغة الروسية إلى الإنجليزية.

وتنح هذه الجامعة شهادة في تقنية المعلومات بعد أن يجتاز الدارس المقررات الدراسية المخصصة بنجاح مع إكمال التدريب الأساسي في علم اللغة الآلي. والمقررات هي:

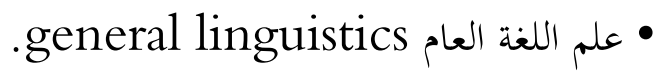

• مقدمة في علم اللغة الآلي Introduction to Computational Linguistic.

• لغات البربة Programming languagse.

• (الذكاء الاصطناعي Artificial Intelligence. (المي http://www.georgetown.edu/departments/linguistics/program/computational.htm. 
• تطبيقات عملية في: الترجمة الآلية واسترجاع المعلومات وتلخيص النصوص وتحليل عملية الكلام. وهذه الشهادة التي تقوم على أساس نظري وتطبيقي تُعُُّ الدارسين للبحث ومواصلة الدراسة في هندسة النظم والمعلومات.

ويُعلُُ هذا المجال جسما غريبا وبجهولا في هيكل اللغويات العربية بالجامعات الإسلامية العربية. فإذا نظرنا في مقرر اللغويات في أقدم جامعة وهي الأزهر لا نجد في مقرراتا مادة واحدة في الحاسوب. 39 بل، وفي أحدث جامعة إسلامية في أكثر البلدان الإسلامية تطورا في تقنية نظم المعلومات -أي ماليزيا- تحظى هذه المادة باهتمام ضئيل، لا يتعدى أن يكون مقدمة تعريفية فقط. وتخلو حتى المعاهد المتخصصة في اللغة العربية من هذا الفرع المهم من علم اللغة. ومثال ذلك معهد الخرطوم الدولي للغة العربية. فهذا المعهد الذي يتبع لأرفع مؤسسة عربية تربوية، وهي المنظمة العربية للتربية والثقافة والعلوم، إحدى منظمات جامعة الدول العربية، تخلو مناهجه من الدراسات الحاسوبية. ورغم أن الحاسوب صار مهما في تدريس اللغات. ويستخدم في التعليم المباشر والتعليم منْ بُعْد فإن الجامعات العربية لا يوجد فيها أي برامج لغوية تقدم بمساعدة الحاسوب. بل ولا توجد دراسة عليا في الجامعات في استخدام الحاسوب في تدريس اللغة العربية Computer Assisted Arabic Programme.

لقد أدى عدم الاهتمام بدور علم اللغة الآلي وتقنية لمعلومات إلى ضآلة نظم وشبكات المعلومات العربية، وأدى كذلك إلى صعوبة البحث في شبكة المعلومات الدولية؛ ولذا فإن معظم المعارف الإسلامية والعربية تخزن بلغات أجنبية.

نعم، إن معظم المعلومات في شبكة المعلومات الدولية تعتمد على استعمال الحرف اللاتيني في البحث والتخزين. فاللغات ذات الحرف اللاتيني لا تحابه بإشكاليات كما تجابه اللغة العربية وتلك التي لا تستخدم

38
39

http://www.frcu.eun.eg/www/universities/html/azhar.html 
الحرف اللاتيني كالصينية، والكورية، والعبرية. ولكن بعضا من هذه اللغات كاليابانية، والصينية، والكورية بل والعبرية قد قطع شوطا كبيرا في التغلب على هذه الإشكاليات.

إن عدم اهتمام أقسام علم اللغة بعلم اللغة الآلي، ترك مجال نظم المعلومات للفنيين الذين يتأهلون من كليات: الهندسة ونظم المعلومات والأقسام الأخرى ذات الصلة بعلوم الحاسوب. وبما أفم غير مؤهلين تأهلا لغويا عاليا فإفم يقعون في أخطاء جسيمة عند تخزين المعلومات باللغة العربية. ويخطئون كذلك في إيجاد المقابل العربي المناسب للمصطلح الأجنبي.

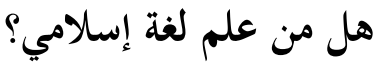

لقد طرح هذا السؤال الذي يجسد أملا محاولة لتجديد الفكر اللغوي العربي الإسلامي، ولإقامة بديل ذي لون إسلامي. وحقيق بنا أن نذكر في هذا المقام أن هذه المحاولة -أي التجديد- ليست طارئة في التفكير العربي فهي دعوة قديمة، وإن انطلقت من منطلقات مختلفة منها القومي ومنها الديني. وهذه الدعوات -وإن اختلفت في غاياها- فهي تتفق في مظهرها وآلياها فالإصلاح في كل الدعوات شامل لكل أفرع اللغة من نهو، وصرف، وبلاغة. كما أنه نخو إصلاح منهج البحث والمحتوى بل وطريقة

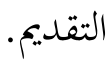

ففي مجال النحو 40 ظهرت دعوات قديمة تشكو من صعوبة النحو. يقول خلف الأحمر: "لما رأيت النحويين وأصحاب العربية أجمعين قد استعملوا التطويل وكثرة العلل وأغفلوا ما يحتاج إليه المتعلم المتبلغ في النحو من المختصر، والطرق العربية، والمأخذ الذي يخف على المبتدئ حفظه ويعمل فيه عقله، ويحيط به فهمه. فأمعنت النظر والفكر في كتاب أؤلفه، وأجمع فيه الأصول والأدوات والعوامل على أصول المبتدئين ليستغني به المتعلم عن التطويل، فعملت هذه الأوراق."41

لقد خصصنا الحديث هنا عن إصلاح النحو فقط وما ذلك إلا لأن الشكوى من صعوبة النحو ومنذ القرن الثاني المجري قد أسفرت

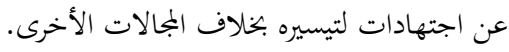
الأهمر، خلف، مقدمة في النحو، (ترجمة عز الدين التنوخي) دمشق: مطبوعات مديرية إحهاء التراث القديم، 1961، ص33. 
ومن الذين نادوا بإصلاح النحو يومئذٍ أبو على الفارسي (ت 377هـ) والذي علق على خلافه مع أبى الحسن الرماني (ت 374ه) بقوله "إن كان النحو ما يقوله الرماني فليس معنا منه شئ. وإن كان النحو ما نقوله نخن فليس معه منه شئ."42 وتلا ذلك ثورة ابن مضاء القرطبي (1195-1119م) على المذهب النحوي التقليدي التي نادى فيها بإلغاء نظرية العامل، والقياس المنطقي، وإلغاء التمارين والتطبيقات الافتراضية.

وتلت تلك المحاولات في العصر الحديث اجتهادات عصرية محافظة بدأها إبراهيم مصطفي في كتابه "إحياء النحو"، وتلتها محاولات أخرى قام هما محدثون رأوا أن إشكالية النحو العربي وكل علوم العربية الأخرى من الممكن تذليلها. وذلك بتطبيق معطيات علم اللغة الحديث. وكان جورجي زيدان رائد هذه المدرسة. وقد حاول أن يعرض شيئا مما تداوله اللغويون في الغرب عن اللغة وطرق تحليلها في كتابيه "الفلسفة اللغوية والألفاظ العربية" و"اللغة كائن حي." وقد قام فعلا بمحاولات أخرى لتذليل النحو العربي على نمط النظرية التوليدية التحويلية.43

وفي هذا العصر الذي انتظمت فيه الصحوة الإسلامية وتمدت، دعا بعض العاملين في حقل اللغويات ذوو النزعة الإسلامية بضرورة البحث عن بديل للعلوم اللغوية يقوم على معايير وقيم الإسلام؛ ليخدم قضايا الأمة، فظهرت دعوات إلى علم لغة شرعي 44 شبيهة بالدعوات التي تدعو إلى أدب إسلامي. والمعروف بداهة أن العلم تراث بشري، وليس إنجازا خاصا بأمة معينة ومن يقول إن المعرفة بما وصلت إليه، قد صُنعتْ فقط في الغرب، ضلّ الحق، وظلم كثيرا من الأمم. فالتاريخ يثبت أن كل أمة من الأمم قد وضعت لبنة في بنية المعرفة. وأن المسلمين قد قاموا بوضع أعظم اللبنات في تاريخ العلم، غير أن الغرب الذي

42 .181|2

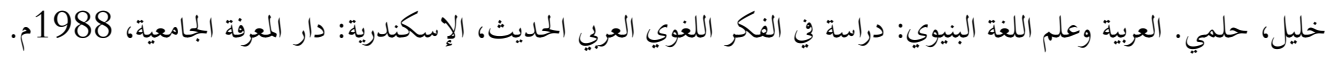
43

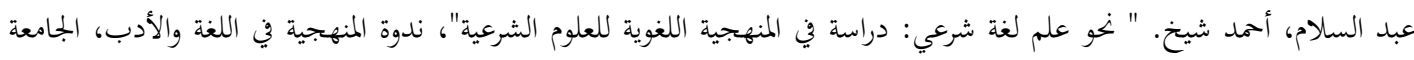

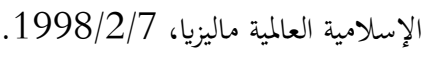


انتهت إليه السيادة العلمية الآن، قد فرض عقيدته، وفلسفته، وقيمه السائدة، على العلوم الإنسانية،

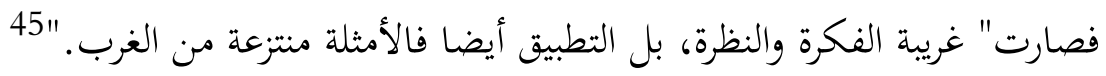

ودخلت تلك العلوم إلى عالمنا الإسلامي، بما فيها من تناقض مع ديننا الحنيف. وقبلها المسلمون كما هي دون تبديل وتعديل. ودفعت هذه الحالة من التبعية الغيورين من علماء المسلمين إلى البحث عن بدائل إسلامية للعلوم الإنسانية والتي أثر فيها التفكير الغربي العلماني فظهرت مصطلحات: كعلم الاجتماع الإسلامي، وعلم الاقتصاد الإسلامي، وعلم النفس الإسلامي، والإعلام الإسلامي، وغيرها من النظم والمعارف.

إن القول بقيام علم لغة إسلامي صرف، يقيم بين المسلمين والآخرين سياجا، مما يؤدي إلى عزلة، تحرم المسلمين من الاستفادة من معطيات الآخرين المفيدة؛ فالحكمة ضالة المؤمن، يأخذها أنى وجدها، فليس كل ما أتى به الغرب شرا. وكما يرى القرضاوي فيجب "أن تكون لنا (مدارس إسلامية) في هذه العلوم: المدرسة

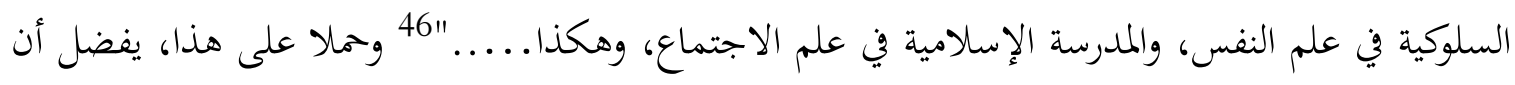
تكون لنا مدارس أو مداخل إسلامية إلى علوم اللغة وآدابها.

إن المدخل الإسلامي أو الإطار الإسلامي في علوم اللغة يجب أن يكون ذا هدف رسالي، يتخذ مصادر المعرفة الإسلامية مرجعية له، ويفسر الظواهر اللغوية بناء على القرآن والسنة مستفيدا من معطيات العلوم الإنسانية التي لا تتعارض مع العقيدة.

إن علم اللغة ذا التوجه الإسلامي يجب ألا يسير خلف علم اللغة علماني النزعة. أو يكون نسخة معربة له، ويردد مقولاته بلا وعي. إذيجب أن تكون له شخصيته واهتماماته.

45
46 


\section{أهم قضايا علم اللغة ذي التوجه الإسلامي}

وبعد فإن الدارس ذي النزعة الإسلامية ينبغي أن يهتم بأهم القضايا التي تمس حاضر ومستقبل الأمة

وتخدم الدين. وهذه القضايا كثيرة. غير أن هذه الدراسة تشير إلى أبرزها وأهمها وهي، مثالا لا حصرا:

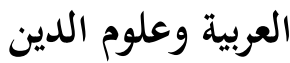

ورد في توصيات مؤتمر علوم الشريعة الذي عقد في عمّان عام 1994 أن "العلاقة بين القرآن الكريم واللغة العربية، وما يتصل بهذه العلاقة من قضايا ذات أهمية بالغة في فهم القرآن الكريم وتطوير اللغة العربية

$$
\text { وفقهها وتوضيح العلاقة بين إطلاقية القرآن ونسبية اللغة العربية."47 ونس }
$$

فالعربية ترتبط بعلوم الدين ارتباط توحد، بحيث لا فكاك منها. ويقول ابن خلدون عن العلاقة بين العلوم اللغوية وعلوم الدين " وأصناف هذه العلوم النقلية كثيرة، لأن المكلف يجب عليه أن يعرف أحكام الله تعالى المفروضة عليه، وعلى أبناء جنسه، وهي مأخوذة من الكتاب والسنة فلا بد من النظر في الكتاب بييان ألفاظه أولا، وهذا هو علم التفسير. ثم بإسناده إلى النبي صلى الله عليه وسلم الذي جاء به من عند الله سبحانه، واختلاف روايات القراء في قراءته، وهذا هو علم القراءات. ثم بإسناد السنة إلى صاحبها، والكلام في الرواة الناقلين لها، ومعرفة أحوالهم، وعدالتهم، ليقع الوثوق بأخبارهم بعلم ما يجب العمل بمقتضاه من ذلك، وهذه هي علوم الحديث. ثم لا بد من استنباط هذه الحكام من أصولها من وجه قانوني يفيد العلم بكيفية هذا الاستنباط، وهذا هو أصول الفقه. وبعد هذا تحصل الثمرة بمعرفة أحكام الله تعالى في أفعال المكلفين، وهذا هو الفقه.. "48

ومن هذا يظهر أن للغة وعلومها واقعا مركزيا في تأسيس برنامج تكاملي "لاستنباط الأحكام الشرعية المعالجة لقضايا الواقع الإنسان، واستكشاف الحقائق العلمية من النصوص القرآنية والحديثية، وتحليل النصوص رك

$$
\begin{aligned}
& 47 \text { بحوث مؤتر علوم الشريعة في الجامعات الإسلامية. تخرير د. فتحي حسن ملكاوي ود. محمد عبد الكريع أبو سل، عمان: جمعية }
\end{aligned}
$$

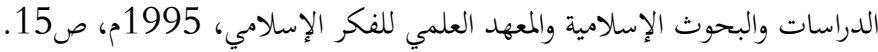

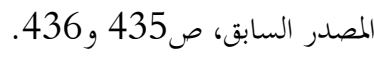


التراثية المبينة لها، وربط الخصائص النظمية والأسلوبية للخطاب الإسلامي بوجه عام بمناهجه في بيان السنن الكونية، وتقديم الحقائق العلمية ومخاطبة العقول، ونقل الأفكار، ومعالجة الأوضاع الإنسانية المتجددة."49 وإيمانا بهذا الارتباط أوجب الراغب الأصفهاني على مفسر كتاب الله أن يتقن عشرة علوم، منها علم اللغة، وعلم الاشتقاق، وعلم النحو، وعلم القراءات، 50 وأضاف السيوطي رحمه تعالى علوما لغوية أخرى منها: علم التصريف، وعلم البيان، وعلم المعاني. فالمفسر الذي لا يتقن هذه العلوم يفسر بالرأي. 51 إذن فالنظر في كتاب الله والحديث الشريف "لا بد أن تتقدمه العلوم اللسانية، لأنه متوقف عليها، وهي أصناف، فمنها علم اللغة وعلم النحو"52 وحري به أيضا أن يدرس علوما عصرية أخرى لم يعاصرها السيوطي، ولا الأصفهاني، منها علوم لغوية، وأخرى غير لغوية. ومن الأولى: علم اللغة النفسي، وعلم اللغة الاجتماعي، وعلم الأسلوب، وتحليل الخطاب.

إن هذه النزعة التكاملية بين علوم الدين وعلوم اللغة ستقود إلى فهم عميق بمقاصد الخطاب الديني. وهذا الفهم العميق سيرْف الأمة بعلماء جديرين بأن يقودوا حركة البعث الحضاري، وإحياء حركة الاجتهاد التي تعطلت منذ أزمان سحيقة.

ومن هنا ينبغي إقامة الدرس اللغوي العربي بما يخدم هذه العلاقة. وخروجا من الإطار النظري إلى فضاء الواقع والتطبيق نجد أن علوم اللغة بصورتا الراهنة فيها كثير من الحشو والإطالة والتكلف وفيها ما لا فائدة منه مثل: الغريب والاستثناء والمهجور. مما يجعل تعلم العربية عسيرا. ولأن القرآن كلام الله، وما يُبنتى رتى من درس العربية وتعلمها هو فهم كلام الله فيجب أن نقيم العربية على ما جاء في كلام الله ورسوله.

$$
\begin{aligned}
& 49 \text { ب عبد السلام، أممد شيخ. "مناهج الدراسات اللغوية الحديثة وتوظيفها في التعامل مع نصوص الوحي" ورقة قدمت إلى الجامعة الإسلامية } \\
& \text { العالمية بماليزيا، } 1977 . \\
& 50
\end{aligned}
$$

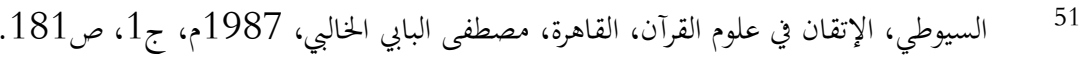

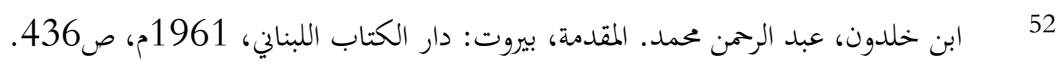


إن الترجمة المنشودة ذات شقين، فهي نقل من العربية وإليها. فاللغة العربية ذات تراث علمي ضخم يتمثل في القرآن والتراث. وهي بهذه تشكل ثروة معرفية هائلة أسهمت وتسهم في الارتقاء بالعقل الإنساني عامة. وكثير من ذلك لا يتم إلا بواسطة الترجمة.

وإذا كان من الممكن ترجمة التراث إلى اللغات الأخرى فإنه من المستحيل ترجمة القرآن إلى أي لغة أخرى كما قال بذلك ابن تيميه. ولذا فإنه يجب ترجمة معانيه.

ولهذه الترجمة من العربية غاية تربوية، وأخرى دعوية. فالجمهور من المسلمين ليست العربية لساغم. وكثير من علماء المسلمين نوه إلى أن علوم الشريعة الإسلامية لا يفهمها حق الفهم إلا من فهم اللغة العربية حق الفهم. 53 منهم: الإمام الشاطبي وابن قتيبة وابن تيميه.

والترجمة من اللغات الأخرى يجب أن توجه لترجمة منجزات العقل البشري في مجال التقنية والعلوم وأن

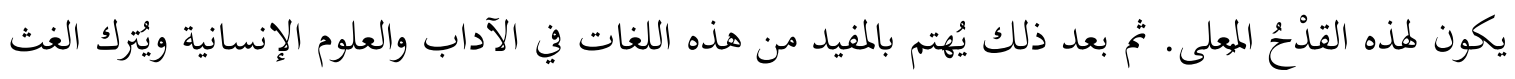

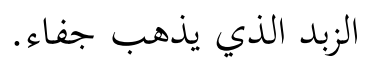

ولذا ولفهم تعاليم الدين الإسلامي فهما صحيحا، ولنقل ثروات الأمم الأخرى في مجال العلوم وغيره، ينبغي أن تَتم المؤسسات التربوية بالارتقاء بدرس الترجمة وإنجاب تراجمة يجيدون العربية واللغات الأخرى المترجم إليها.

التعريب

إن تلقي المعرفة بلسان أجنبي ذو مثالب عديدة منها أن الاستيعاب لا يكون في مستوى حالة التلقي باللغة الأم. وقديما فطن إلى ذلك علماء الأمة. يقول ابن خلدون "والأعجمي المتعلم للعلم في الملة الإسلامية

$$
\begin{aligned}
& 53 \text { العلواني، طه جابر. محاضرة بعنوان "عربية القرآن: لا دخيل في القرآن الكريع". (تلخيص وعرض عبد الله أمد بن همدي). المعهد العلمي } \\
& \text { للفكر الإسلامي، } 21 \text { مايو 2001م، أنظر ذلك في: }
\end{aligned}
$$

http://iiit.org/Ar/conferences/QuranicArabic.htm 
يأخذ العلم بغير لسانه الذي سبق إليه ومن غير خطه الذي يعرف ملكته. فلهذا يكون ذلك حجابا كما قلناه."54 ويستمر قائلا: "حتى إن طالب العلم من أهل هذه الألسن (البربري والفارسي والرومي والإفرنج) إذا طلبه من أهل اللسان العربي ومن كتبهم جاء مقصرا في معارفه عن الغاية والتحصيل وما ذلك إلا من قبل اللسان."55 فالإنسان الذي يفكر بلغته أكثر قدرة على الإبداع وصنع الحضارة وما يكن العربي مبدعا فإنه سيبقى مستهلكا للحضارة، عاجزا عن صناعتها. إن علم اللغة يجب أن يقود حركة التعريب. وذلك لاستعادة الهوية العربية وللقضاء على التخلف. ولن تفلح حركة تعريب لم تبن على أسس لغوية وعلمية. فحركة التعريب "جمدت عند توقف الاجتهاد اللغوي وانخسار العربية، وانغلاقها في قوالب محنطة."

الحخلاصة

من هذا العرض يتضح بجلاء خصوصية قراءة الوحي للغة العببية كما يتضح كذلك مدى أهمية القراءة الكونية لعلوم اللغة العربية. فقراءة العربية قراءة وحي هي قراءة للتأصيل في المنهجية وذلك لإحياء المنهجية التراثية التي من الممكن استخدامها في هذا العصر وتقديمها للعالم مرة أخرى في ثوب عصري. كما أغها إعادة لقراءة الواقع اللغوي وذلك لتنقيته من المؤثرات الفكرية المتعارضة مع مبادئ الدين الإسلامي الحنيف. وما ذلك إلا لأن اللغة في الواقع الإسلامي لا تدرس لذاتا، ولا لغاية دنيوية فقط وإنما تدرس كوسيلة لفهم العقيدة وفهم مقاصد الشرع ومن ثم تقديم الفهم الإسلامي الصائب حتى لا يكون العجز اللغوي عائقا في فهم الإسلام.

أما القراءة الكونية فقد أظهرت مدى البون الشاسع بين الدرس اللغوي المعاصر الذي استفاد من معطيات التقنية وبين الدرس اللغوي العربي الذي ما زال محنطا في منهجية بالية. وما زالت قضاياه لا تمت

$$
\begin{aligned}
& 54 \text { } 55 \\
& 55 \\
& 56 \text { الصيادي، عحمد المنجي. "التعريب في الوطن العربي"، مؤتمر التعريب، بيروت: مركز دراسات الوحدة، 1986، ص1097. }
\end{aligned}
$$


لهذا العصر بصلة. ومن هنا وجب استشراف منهجية عصرية وقضايا عصرية جديدة تستفيد من معطيات علم اللغة بصورتا المعاصرة وتستلهم من خلال قراءة الوحي مقاصد الإسلام وقيمه العليا في التوحيد والتزكية والعمران. و الله الموفق وهو المستعان. 